\title{
PREANAESTHETIC MEDICATION WITH DIFFERENT DOSES OF INTRANASAL MIDAZOLAM: A RANDOMIZED CLINICAL STUDY IN CHILDREN
}

\author{
Mukesh Somvanshi ${ }^{1, *}$, Archana Tripathi ${ }^{2}$, Anil Rajoriya ${ }^{3}$ \\ ${ }^{1}$ Associate Professor, ${ }^{2}$ Professor, ${ }^{\mathbf{3}} \mathrm{Ex}$-resident, Department of Anaesthesiology and \\ Critical Care, Government Medical College \& Associated Group of Hospitals, Kota - 324005
}

*Correspondence Author:

E-mail: mukeshsomvanshi@ymail.com

\begin{abstract}
Background: Midazolam is often used for premedication in children. We investigated the efficacy of different doses of intranasal midazolam for premedication in 75 children, ASA physical status I and II, aged 3 to 10 years of either sex undergoing various elective surgical procedures.

Methods: In a randomized, double blind, placebo controlled design, all children were allocated to one of the three groups of 25 each. Group - A received $0.2 \mathrm{mg} / \mathrm{kg}$ intranasal midazolam $(5 \mathrm{mg} / \mathrm{ml})$. Group - B received $0.3 \mathrm{mg} / \mathrm{kg}$ intranasal midazolam $(5 \mathrm{mg} / \mathrm{ml})$. While Group $-C$ received intranasal normal saline. After 20 minutes of premedication, sedation scores and ease of separation from parents were noted. Children's response at the time of intravenous cannulation and face mask application was also measured.

Results: Sedation scores in group $A$ and $B$ were excellent ( $3.64 \pm 0.5 \& 3.76 \pm 0.7$ respectively) compared to group $C(1.24 \pm 0.4)$. Separation of children from their parents was easier in group $A \& B$ than in Group $C$. In group $A \& B$, children were calm on intravenous cannulation and face mask application.

Conclusion: We conclude that intranasal midazolam is effective and very well accepted premedication drug in children.
\end{abstract}

Key words: Children, Premedication, Intranasal route and Midazolam.

\section{BACKGROUND}

Administration of anaesthesia to children is a challenge for the anaesthesiologist. A calm and quiet child is necessary to separate them from their parents and to put on intravenous line for a smooth anaesthesia induction. For this, premedication may be required and it needs to be in an acceptable form, to have a rapid onset with minimum side effects.

Midazolam, a water soluble benzodiazepine, has a number of advantages for the conscious sedation for young children prior to general anaesthesia. Various routes have been used for midazolam administration. However, each route has disadvantages. ${ }^{1-5}$ Intranasal route has been of interest since a long time and has the advantage of faster and reliable onset of action ${ }^{6}$, ease of administration and no fear of needle prick.

Taking in to consideration of good premedicant property of midazolam and the advantage of intranasal route, this double blind study had been planned to compare intranasal midazolam in two different doses with control group.

\section{METHODS}

After hospital's ethical committee's approval and written informed consent from the parents, we investigated 75 children of ASA physical status I and II, aged 3 to 10 years of either sex who were undergoing various surgical procedures. Exclusion criteria were history of upper respiratory tract infection, nasal secretions or bleeding, presence of nasal pathology, emergency surgery and parental or child refusal.

Children were randomly divided in to three groups of 25 each as follows: Group A received $0.2 \mathrm{mg} / \mathrm{kg}$ intranasal midazolam $(5 \mathrm{mg} / \mathrm{ml})$. Group - B received $0.3 \mathrm{mg} / \mathrm{kg}$ intranasal midazolam $(5 \mathrm{mg} / \mathrm{ml})$. While Group - C received intranasal normal saline $1.5 \mathrm{ml}$.

The premedicant drugs were diluted with normal saline to reach $1.5 \mathrm{ml}$ in $2 \mathrm{ml}$ 
syringe and instilled in nares (dose splits between either nares). All observers were blinded to the treatment given. At 20 minute after the intranasal dose, sedation was assessed on 6 point Ramsay Sedation scale ${ }^{7}$ (Table 1). Ease of separation from parents was noted on 3 point scale as follows: Poor $=$ Anxious / combative, Good = Anxious / easily reassured and Excellent $=$ Calm / Drowsy. On arrival in operation theatre, intravenous cannulation was performed using $22 \mathrm{G}$ cannula and intravenous induction was performed. Response to intravenous cannulation was assessed on binary scale (Crying / Calm). A 5 point scoring system was used for evaluation of acceptance of face mask application is as follows:

1. Agitated, refuse mask

2. Alert, initially refuse then accepts

3. Calm and accepts mask

4. Drowsy and accepts mask

5. Asleep and accepts mask

After surgery, anaesthetic agents were discontinued and the children were transported to the recovery room.

Table 1: Ramsay Sedation scale for Sedation Assessment

\begin{tabular}{|l|l|}
\hline Score & Response \\
\hline 1 & Patient awake and anxious, agitated, and/or restless \\
\hline 2 & Patient awake, cooperative, accepting ventilation, oriented and tranquilized \\
\hline 3 & Patient awake, responds to commands only \\
\hline 4 & Patient asleep, brisk response to light glabellar tap or loud auditory stimulus \\
\hline 5 & $\begin{array}{l}\text { Patient asleep, sluggish response to light glabellar tap or loud auditory } \\
\text { stimulus but does respond to painful stimulus }\end{array}$ \\
\hline 6 & Patient asleep, no response to light glabellar tap or loud auditory stimulus \\
\hline
\end{tabular}

Data were analyzed using Student's t test and Chi square test and $p$ value $<0.05$ was considered statistically significant.

\section{RESULTS}

Children in three groups were statistically similar in terms of age, weight, type of anaesthesia and surgery (Table 2).

Table 2: Patient characteristics. Results are expressed as mean \pm SD and $(n)$ is number of children

\begin{tabular}{|c|c|c|c|}
\hline & Group A $(n=15)$ & Group B $(n=25)$ & Group C (n=25) \\
\hline Age (yrs) & $6.16 \pm 2.35$ & $5.36 \pm 2.19$ & $6.28 \pm 2.18$ \\
\hline Weight (kg) & $15.78 \pm 3.1$ & $14.53 \pm 2.98$ & $16.0 \pm 2.69$ \\
\hline Gender (Male/Female) & $20 / 5$ & $18 / 7$ & $19 / 6$ \\
\hline Type of surgery (n) & & & \\
\hline ENT surgery & 4 & 4 & 11 \\
\hline Gen. surgery & 13 & 12 & 4 \\
\hline Urological surgery & 4 & 5 & 4 \\
\hline Neurosurgery & 1 & 1 & \\
\hline Orthopaedic surgery & 3 & 3 & \\
\hline
\end{tabular}

At 20 minutes, in group A and B, children showed statistically different sedation scores when compared to group C $(\mathrm{p}<0.05)$. However, sedation scores in group A and B were statistically similar (Table 3 ).

Table 3: Sedation score at 20 min. mean \pm SD

\begin{tabular}{|c|c|}
\hline Groups & Sedation score \\
\hline Group A & $3.64 \pm 0.5$ \\
\hline Group B & $3.76 \pm 0.7$ \\
\hline Group C & $1.2 \pm 0.4^{*}$ \\
\hline \multicolumn{2}{|c|}{ P $<0.05$ group A \& B v/s group C } \\
\hline
\end{tabular}


On separation from parents, $60 \%$ children in group A and $72 \%$ children in group B showed excellent response and easily separable from their parents whereas none of the children in group $C$ showed excellent response $(\mathrm{p}<0.05)($ Table 4$)$.

Table 4: Response to parental separation

\begin{tabular}{|c|c|c|c|c|c|c|}
\hline \multirow{2}{*}{ Response } & \multicolumn{2}{|c|}{ Group A } & \multicolumn{2}{c|}{ Group B } & \multicolumn{2}{c|}{ Group C } \\
\cline { 2 - 7 } & No. & $\%$ & No. & $\%$ & No. & $\%$ \\
\hline Poor & 2 & 8 & 1 & 4 & 20 & 80 \\
\hline Good & 8 & 32 & 6 & 24 & 5 & 20 \\
\hline Excellent & 15 & 60 & 18 & 72 & 0 & 0 \\
\hline
\end{tabular}

Majority of children in group A and B were calm, allowed intravenous cannulation and accepted face mask very well, while in group $C$, every child was crying (Table $5 \& 6$ ). No child became excessively sleepy. No side effects were observed and there were no complication related to nasal route of administration.

Table 5: Response to intravenous cannulation

\begin{tabular}{|c|c|c|c|c|c|c|}
\hline \multirow{2}{*}{ Response } & \multicolumn{2}{|c|}{ Group A } & \multicolumn{2}{c|}{ Group B } & \multicolumn{2}{c|}{ Group C } \\
\cline { 2 - 7 } & No. & $\%$ & No. & $\%$ & No. & $\%$ \\
\hline Crying & 5 & 20 & 4 & 16 & 25 & 100 \\
\hline Calm & 20 & 80 & 21 & 84 & 0 & 0 \\
\hline
\end{tabular}

Table 6: Response to face mask application

\begin{tabular}{|c|c|c|c|c|c|c|}
\hline \multirow[t]{2}{*}{ Score } & \multicolumn{2}{|c|}{ Group A } & \multicolumn{2}{|c|}{ Group B } & \multicolumn{2}{|c|}{ Group C } \\
\hline & No. & $\%$ & No. & $\%$ & No. & $\%$ \\
\hline 1 & 2 & 8 & 1 & 4 & 17 & 68 \\
\hline 2 & 3 & 12 & 3 & 12 & 7 & 28 \\
\hline 3 & 16 & 64 & 15 & 60 & 1 & 4 \\
\hline 4 & 4 & 16 & 6 & 24 & 0 & 0 \\
\hline 5 & 0 & 0 & 0 & 0 & 0 & 0 \\
\hline
\end{tabular}

\section{DISCUSSION}

Anaesthesia and surgery is a very stressful condition for most of children. Premedication agents are required to reduce the fear of anaesthesia and surgery and to allow easy separation of children from their parents. There is a continuous search for the ideal premedication agent and also for the best route of administration of these drugs in children. A premedication agent must have an acceptable and atraumatic route of administration. Premedication may be administered orally, intramuscularly, intravenously, rectally, nasally or sublingually. Although, most of these routes are effective and reliable, each has drawback as well. There is still no ideal premedication agent or ideal route of administration.

Advances in pharmacology have provided a number of premedication agents in children. Midazolam is the most commonly used agent in this group of patients. It has been reported to produce amnesia, sedation, reduce separation anxiety and facilitate smooth induction of anaesthesia. This drug has been given by almost every route i.e. orally, intramuscularly, intravenously, rectally, nasally or sublingually with variable success. ${ }^{8-10}$

The intranasal route for midazolam administration was chosen for the present study because of its various advantages, prominent among them being: avoidance of painful injections, non-invasive method and faster onset of action. Nasal mucosa is an area of rich blood supply which allows absorption of drug directly in to systemic circulation with no first pass effect.11-14 The intranasal midazolam has been found to be safe up to a dose of $0.5 \mathrm{mg} / \mathrm{kg} \cdot{ }^{15-17}$ The bioavailability of intranasal route has been reported $57 \% .^{18}$

This study was designed to evaluate the effect of midazolam, given intranasally, on children behavior and response at time of 
separation from their parents, at intravenous cannulation and face mask application. Our study demonstrates that in both doses used, intranasal midazolam produces anxiolysis and sedation in children with rapid onset. A significant change in behavior was evident with both midazolam doses at 20 minutes and this was maintained till induction of anaesthesia. Most of the children became calm allowing easy separation from their parents. The response to intravenous cannulation and face mask application was excellent, therefore a smooth induction was possible. None of the children became excessively sleepy during the study. Children in control group, who were agitated prior to intranasal administration of drug remained agitated till induction.

\section{CONCLUSIONS}

We conclude that intranasal midazolam is effective and very well accepted as premedication agent by children. However, no additional benefit was observed from higher dosage, thus we recommend using lower dose of $0.2 \mathrm{mg} / \mathrm{kg}$ midazolam intranasally.

\section{AUTHOR'S CONTRIBUTION}

\begin{tabular}{|l|l|l|l|}
\hline & Contributor 1 & Contributor 2 & Contributor 3 \\
\hline Concepts & $\sqrt{ }$ & & \\
\hline Design & $\sqrt{ }$ & $\sqrt{ }$ & \\
\hline Data acquisition & $\sqrt{ }$ & & $\sqrt{ }$ \\
\hline Statistical analysis & $\sqrt{ }$ & $\sqrt{ }$ & \\
\hline Manuscript preparation & $\sqrt{ }$ & $\sqrt{ }$ & $\sqrt{ }$ \\
\hline Manuscript editing & $\sqrt{ }$ & $\sqrt{ }$ & \\
\hline Manuscript review & $\sqrt{ }$ & $\sqrt{ }$ & \\
\hline Manuscript approval & $\sqrt{ }$ & $\sqrt{ }$ & $\sqrt{ }$ \\
\hline
\end{tabular}

\section{ACKNOWLEDGMENTS}

Authors wish to thanks Mr. Anshul for his assistance in the statistical analysis of data.

\section{REFERENCES:}

1. Rochette A, Julia JM, Evrard O, Ricard C, Jullien Y, DuCailer J. Intramuscular Midazolam as premedication in newborn children and infants. Ann Fr Reanim 1984; 3: 346-50

2. Taylor MB, Vine PR, Hatch DJ. Intramuscular Midazolam premedication in small children. Anaesthesia 1986; 41: 21-6

3. Saint-Maurice G, Esteve C, Holzer J, Camer O, Rey E, DeLautine D. Pre-medication with rectal midazolam. Effective dose in paediatric anaesthesia. Ann Fr Anaesth Reanim 1984; 3: 181-4

4. Rita L, Seleny FL, Mazurek A, Rabins R. Intramuscular Midazolam for pediatric preanesthetic sedation: A double blind controlled study with morphine. Anesthesiology 1985; 63: 528-31

5. Raybould D, Bradshaw EG. Premedication for day case surgery. $1987 ; 42: 591-5$

6. Shela SA, Al-Sharheed MA, Abdelhalim AA. Intranasal Dexemedetomidine vs Midazolam for premedication in children undergoing complete dental rehabilitation: a double-blinded randomized controlled trial. Paediatr Anaesth 2014; 24: 181-9

7. Hansen-Flaschen J, Cowen J, Polomano RC. Beyond the Ramsay Scale: Need for a validated measure of sedating drug efficacy in the intensive care unit. Crit Care Med 1994; 22: 732-3

8. Dallman JA, Ignelzi MA Jr, Briskie DM. Comparing the safety efficacy and recovery of intranasal midazolam vs. oral chloral hydrate and promethazine. Pediatr Dent 2001; 23 (5): 424-30

9. Christy L, Richard DU, Stanley FM, David LG, Jane LF. Midazolam Premedication in Children: A Pilot Study Comparing Intramuscular and Intranasal Midazolam Administration. Anesth Prog 2005; 52: 5661.

10. Panchal J, Kakkad K, Kariya P, Patel P. Comparative Study of Intranasal Midazolam and Intravenous Benzodiazepines in Control of Seizures in Children, Natl J Med Res 2013; 3: 30-33

11. Wilton NC, Leigh J, Rosen DR, Pandit UA. Preanesthetic sedation of preschool children using intranasal midazolam. Anesthesiology 1988; 69: 972-5

12. Walberg EJ, Wills RJ, Eckhert J. Plasma concentration of midazolam in children following intranasal administration. Anesthesiology 1991; 74: 233-5 
13. Rey E, Delaunay L, Pons G, Muratk I, Richard M, Sainte-Maurice C, Olive G. Pharmacokinetics of midazolam in children - comparative study of intranasal and intravenous administration. Eur J Clin Pharmacol 1991; 41: 355-7

14. Bjorkman G, Rigemar G, Idvall J. Pharmacokinetics of midazolam given as an intranasal spray to adult surgical patients. Br J Anaesth 1997; 79: 575-80

15. Yealy D, Ellis J. Intranasal midazolam as a sedative for children during laceration repair. Am J Emerg Med 1992; 10: 584-7.

16. Bozkurt P, Kilic N. The effects of intranasal midazolam on urodynamic studies in children. Br $\mathrm{J}$ Urol 1996; 78: 282-6.

17. Fosel T. Hack C, Knoll R. Nasal midazolam in children, plasma concentrations and the effect on respiration. Paediatr Anaesth 1995; 5: 347-53.

18. Rey E, Delaunay L. Pharmacokinetics of midazolam in children: comparative study of intranasal and intravenous administration. Eur J Clin Pharmacol 1991; 41: 355-7. 